\title{
Equation to predict feed intake response by lactating cows to factors related to the filling effect of rations
}

\author{
M. S. Allen, ${ }^{1 *}$ D. O. Sousa,${ }^{1,2} \dagger$ and M. J. VandeHaar ${ }^{1}$ \\ ${ }^{1}$ Department of Animal Science, Michigan State University, East Lansing 48824 \\ ${ }^{2}$ Department of Animal Science, University of São Paulo, Pirassununga, SP, 13635-900 Brazil
}

\section{ABSTRACT}

Our objective was to predict the dry matter intake (DMI) response during ration formulation to factors related to the filling effect of rations and their interaction with milk yield (MY) by lactating cows past peak lactation. A data set was developed consisting of 134 treatment means from 34 experiments reported in 32 peer-reviewed articles published from 1990 through 2015. The data set included data for cows ranging from 60 to 309 d postpartum with mean DMI ranging from 17.6 to $30.6 \mathrm{~kg} / \mathrm{d}$ and MY ranging from 20.3 to 51.1 $\mathrm{kg} / \mathrm{d}$. Ration composition among treatments ranged from 12.7 to $21.8 \%$ of dry matter (DM) for crude protein, 11.5 to $31.0 \%$ of DM for acid detergent fiber (ADF), 25.5 to $48.2 \%$ of DM for neutral detergent fiber (NDF), 9.9 to $39.3 \%$ of DM for forage NDF (FNDF), and 0.45 to 0.84 for the ratio of $\mathrm{ADF} \%$ to $\mathrm{NDF} \%$ (ADF/NDF). Laboratory measures of digestibility of NDF (in vitro or in situ, FNDFD) for the sole or major forage ranged from 24.1 to $72.7 \%$. The model included the random effect of study to account for various experiment-specific effects including different methods of measurement of NDF and FNDFD among studies. The full model also included linear and quadratic effects of crude protein, $\mathrm{ADF}, \mathrm{NDF}, \mathrm{FNDF}, \mathrm{ADF} / \mathrm{NDF}$, and FNDFD, as well as their linear and quadratic interactions, and mean MY for each study and its interaction with ration factors. The proposed prediction equation is DMI $(\mathrm{kg} / \mathrm{d})$ $=12.0-0.107 \times \mathrm{FNDF}+8.17 \times \mathrm{ADF} / \mathrm{NDF}+0.0253$ $\times$ FNDFD $-0.328 \times(\mathrm{ADF} / \mathrm{NDF}-0.602) \times(\mathrm{FNDFD}$ $-48.3)+0.225 \times \mathrm{MY}+0.00390 \times(\mathrm{FNDFD}-48.3)$ $\times(\mathrm{MY}-33.1)$ with mean bias $=0.00 \mathrm{~kg} / \mathrm{d}$, root mean square error $=1.55 \mathrm{~kg} / \mathrm{d}$, and concordance correlation coefficient $=0.827$. Dry matter intake was positively related to $\mathrm{MY}$ and $\mathrm{ADF} / \mathrm{NDF}$ and negatively related to FNDF, and FNDFD was positively related to DMI

Received December 14, 2018.

Accepted May 11, 2019.

*Corresponding author: allenm@msu.edu

$\dagger$ Present address: Department of Animal Environment and Health, Swedish University of Agricultural Sciences, Skara, Sweden 53223. for cows with high MY but negatively related to MY for cows with low MY. In addition, DMI was positively related to FNDFD for low $\mathrm{ADF} / \mathrm{NDF}$ but negatively related to FNDFD for high ADF/NDF. The ADF/NDF was included to represent differences in forage fragility between grasses and legumes. The proposed model was compared with the equation recommended by the National Research Council (2001) that was developed using only animal factors by fitting each equation to a subset of the data set that included the required inputs for both. The National Research Council (2001) equation without diet factors had a higher root mean square error and over-predicted DMI at high DMI and under-predicted DMI at low DMI. Our proposed equation should be useful to predict DMI response to factors related to the filling effects of rations during ration formulation.

Key words: rumen fill, ration formulation, forage quality

\section{INTRODUCTION}

Accurate prediction of DMI is important for ration formulation. Feed intake is related to the energy required for milk yield (MY), maintenance, pregnancy, and change in body reserves. The DMI equation recommended by the 7 th revision of the Nutrient Requirements of Dairy Cattle (NRC, 2001) included only animal factors that could be easily measured or known (i.e., FCM, BW, and week of lactation). Dietary components were not included because the committee reasoned that the approach most commonly used in formulating dairy cattle rations is to establish requirements and an estimate of DMI before ration ingredients are considered. Therefore, the predicted DMI represents the mean effects of diet and its interaction with animal factors for the database used to develop the equation. Actual DMI might differ from predicted because of the potentially large effects of diet on DMI that are not accounted for when using only animal factors (Allen, 2000). Whereas an estimate of DMI that is independent of diet effects is useful to begin ration formulation, a prediction of the effects of ration composition on DMI 
is valuable to assess effects of changes in ration composition during ration formulation. Many equations have been developed that have included both animal and ration factors and have been extensively reviewed by Ingvartsen (1994). More recently, equations have been evaluated by Huhtanen et al. (2011) and Krizsan et al. (2014) for applicability to Nordic conditions. However, although previous equations have included both animal and ration factors they have not accounted for the greater limitation of DMI as MY increases (Allen, 2014). Whereas distention of undigested feed residues in the gastrointestinal tract is a major factor limiting feed intake of lactating cows (Allen, 1996), the extent to which ruminal distention limits DMI is affected by energy demands, determined primarily by MY. The primary factors affecting the filling effects of rations are forage NDF content, the digestibility of forage NDF within a forage family, and fragility of forage NDF (Allen, 2000). Forage NDF digests and passes more slowly than other diet components and its turnover rate in the rumen is affected by differences in digestibility and fragility that affect particle size reduction and passage from the rumen. Previous equations have not included measures of forage NDF digestibility, which is now commercially available, interactions among ration factors, interactions between ration factors and DMI, or ADF / NDF, which might account for differences in forage fragility. Our objective was to predict DMI response to factors related to the filling effect of rations for lactating cows past peak lactation using variables that are available by analyses from commercial laboratories. We hypothesized that inclusion of factors related to the filling effects of diets would improve the prediction of DMI of lactating cows.

\section{MATERIALS AND METHODS}

\section{Data Set Development}

Data were collected from published, peer-reviewed articles that compared forages fed to lactating dairy cows and reported DMI and a laboratory measure of forage NDF digestibility (FNDFD, in vitro or in situ). Searches were conducted using Google (https://scholar .google.com/) and PubMed (https://www.ncbi.nlm.nih .gov/pubmed), as well as the websites of the following journals: Journal of Dairy Science (https://www .journalofdairyscience.org/), Animal Feed Science and Technology (http://www.sciencedirect.com/science/ journal/03778401), Animal (https://www.cambridge .org/core/journals/animal), and Journal of Animal Science (https://academic.oup.com/jas). References of identified articles were screened for additional articles. Initially, 127 peer-reviewed articles were evaluated for potential inclusion in the data set. Selection criteria included experiments that reported mean and variance for DMI, as well as MY, BW, a laboratory measure of NDF digestibility of the primary forage, and diet composition including $\mathrm{CP}, \mathrm{ADF}, \mathrm{NDF}$, and forage NDF concentration. Forage ADF concentration was not included because it was generally not reported. Corresponding authors were contacted to obtain missing information for several potential candidate experiments. Experiments that were conducted during the postpartum period were not considered because control of feed intake is likely dominated by metabolic mechanisms and not limited by distension. Most of the experiments reporting the required information were crossover designs and began post-peak lactation. There were no randomized design experiments that started less than 60 DIM that reported the required information. The final data set of 134 treatment means from 34 experiments reported in 32 peer-reviewed articles published from 1990 through 2015 (Supplemental Table S1; https://doi.org/10.3168/ jds.2018-16166) included data for cows ranging from 60 to 309 d postpartum with mean DMI ranging from 17.6 to $30.6 \mathrm{~kg} / \mathrm{d}$ and MY ranging from 20.3 to 51.1 $\mathrm{kg} / \mathrm{d}$. Ration composition among treatments ranged from 12.7 to $21.8 \%$ of $\mathrm{DM}$ for CP, 11.5 to $31.0 \%$ of $\mathrm{DM}$ for ADF, 25.5 to $48.2 \%$ of DM for NDF, 9.9 to $39.3 \%$ of DM for forage NDF (FNDF), and 0.45 to 0.84 for the ratio of ration concentrations of $\mathrm{ADF}$ to NDF (ADF/ NDF). Forages included corn silage, sorghum silage, alfalfa silage, alfalfa hay, grass silage, and grass hay. Laboratory measures of digestibility of NDF (in vitro or in situ, FNDFD) for the sole forage or major forage ranged from 24.1 to $72.7 \%$ of FNDF. A summary of the data set is shown in Table 1. Distributions were unimodal and continuous for all variables. Goodnessof-fit (Shapiro-Wilk W test) showed all variables to be normally distributed except FNDFD and MY, which were asymmetrical. The distribution for FNDFD was slightly left-skewed (skewness of -0.41) and the distribution for MY was slightly right-skewed (skewness of 0.48). These distributions are likely reflective of what would be observed in practice because there is often a tradeoff in forage yield for very high FNDFD (often less-mature for perennial forages) that producers are unwilling to accept and cows with low MY are dried-off or culled from the herd.

\section{Model Development}

All modeling processes were performed using JMP Pro v. 14.1 (SAS Institute Inc., Cary, NC). Dry matter intake was the dependent variable and was weighted by the reciprocal of its variance within study. The full model included mean MY within study, BW, as well as 
ration concentrations of $\mathrm{CP}, \mathrm{ADF}, \mathrm{NDF}, \mathrm{FNDF}$, and diet $\mathrm{ADF} / \mathrm{NDF}$ and FNDFD as continuous variables, their squares and interactions, and their interactions with the mean MY within study. The ratio of ADF to NDF concentration of rations was calculated and included in the model to account for differences in forage type because DMI of rations containing legume forages is generally higher than with grass forages (Oba and Allen, 1999b). Mean MY for each study was included because distention likely becomes a more dominant mechanism limiting DMI as MY increases (Allen, 2014). Continuous predictor variables were centered for interactions and polynomials. The full model was reduced by forward and backward stepwise regression and the model reduced by backward elimination was selected based on lower Bayesian information criterion. Variance inflation factor (VIF) was evaluated and factors would be removed if VIF $>10$, but none required removal. The stepwise regression procedure does not allow for the specification of random effects so the model selected by this step included fixed effects only. The random effect of study was included in the model to account for other experiment-specific variation such as feeding management, genetic merit, environmental conditions, and differences in laboratory techniques for measurement of ration composition. The interaction of study and FNDFD was included in the model to further account for differences in measurement method for FNDFD. The final model was evaluated by root mean square error (RMSE), mean bias, and concordance correlation coefficient (CCC). The final equation was validated by a 5 -fold across study cross-validation. The data were partitioned across, rather than within, studies into 5 nearly equal-sized subsets each involving all data from $\sim 20 \%$ of the studies, such that for each of the
5 folds, 4 of these subsets were used for training with the remaining subset used for validation.

The proposed model was compared with the equation recommended by NRC (2001) that was developed using only animal factors by fitting each equation to a subset of the data containing all observations that included $4 \%$ FCM, BW, and week of lactation. The fit of the equations to the data was evaluated by RMSE, mean bias, and CCC.

\section{RESULTS AND DISCUSSION}

Correlations among variables are shown in Table 2. Dry matter intake was positively correlated with MY $(\mathrm{r}=0.776)$ and ration $\mathrm{ADF} / \mathrm{NDF}(\mathrm{r}=0.324)$, negatively correlated with NDF $(\mathrm{r}=-0.363)$ and FNDF $(-0.286)$ concentrations of rations, but not correlated with ration $\mathrm{CP}$ or $\mathrm{ADF}$ concentrations or FNDFD. Ration NDF, ADF, and FNDF concentrations were all positively correlated $(\mathrm{r}>0.46)$, ration ADF concentration was positively correlated with ration $\mathrm{ADF} / \mathrm{NDF}$ ( $\mathrm{r}$ $=0.727$ ), and ration $\mathrm{CP}$ concentration was negatively correlated with ration NDF and FNDF concentrations $(\mathrm{r}<-0.24)$ and positively correlated with FNDFD ( $\mathrm{r}$ $=0.265)$.

Parameter estimates with standard errors, significance, and VIF are shown in Table 3. Concentrations of $\mathrm{CP}, \mathrm{ADF}$, and NDF and their interactions as well as BW and all quadratic terms were eliminated during the stepwise procedure. The random effect of study was significant $(P<0.01)$ and retained in the final model but its interaction with FNDFD was not $(P=$ $0.53)$ and was excluded. The VIF was less than 1.9 for all variables, which was deemed acceptable. The final equation included FNDF, ADF/NDF, FNDFD, MY,

Table 1. Description of variables collected from peer-reviewed publications and included in the data set of 134 treatment means used in the random regression analysis

\begin{tabular}{llcccc}
\hline Item & Variable $^{1}$ & Mean $^{2}$ & $\mathrm{SD}^{2}$ & Minimum $^{2}$ & Maximum $^{2}$ \\
\hline Animal factors & DMI, kg/d & 23.0 & 2.8 & 17.6 & 30.6 \\
& DIM & 107 & 48 & 60 & 309 \\
& MY, kg/d & 32.0 & 7.7 & 20.3 & 51.1 \\
& MY (mean), kg/d & 32.0 & 7.5 & 22.5 & 49.7 \\
Ration factors & BW, kg & 173.8 & 59 & 497 & 765 \\
& CP, \% of DM & 34.1 & 4.6 & 12.7 & 21.8 \\
& NDF, \% of DM & 20.5 & 4.0 & 25.5 & 48.2 \\
& ADF, \% of DM & 0.600 & 0.083 & 0.450 & 31.0 \\
& ADF/NDF & 23.9 & 5.7 & 9.9 & 39.3 \\
& FNDF, \% of DM & 52.0 & 12.3 & 24.1 & 72.7 \\
\hline
\end{tabular}

${ }^{1} \mathrm{MY}=$ milk yield; $\mathrm{MY}$ (mean) = mean of milk yield within study; $\mathrm{ADF} / \mathrm{NDF}=$ ratio of ADF to NDF in ration; FNDF = forage NDF; FNDFD = laboratory measure of forage NDF digestibility.

${ }^{2}$ Mean, SD, minimum, and maximum are from the treatments except MY, which is the mean of milk yield within study. 
Table 2. Correlations among input variables (below the diagonal) and their significance ( $P$-value; above the diagonal)

\begin{tabular}{lrrrrrrrr}
\hline Item & DMI & MY & CP & NDF & ADF & ADF $/$ NDF & FNDF & FNDFD \\
\hline DMI & & $<0.001$ & 0.17 & $<0.001$ & 0.76 & 0.001 & $<0.001$ \\
MY & 0.776 & & 0.27 & $<0.001$ & 0.21 & 0.08 & 0.03 \\
CP & 0.120 & -0.095 & & $<0.01$ & 0.33 & 0.18 & $<0.01$ \\
NDF & -0.363 & -0.311 & -0.246 & & $<0.001$ & 0.68 & $<0.001$ \\
ADF & -0.027 & -0.110 & -0.085 & 0.703 & & $<0.01$ & $<0.17$ \\
ADF/NDF & 0.324 & 0.150 & 0.117 & 0.037 & 0.727 & & 0.22 \\
FNDF & -0.286 & -0.192 & -0.270 & 0.517 & 0.465 & 0.150 & 0.08 \\
FNDFD & 0.076 & 0.125 & 0.265 & -0.120 & -0.107 & -0.078 & -0.012 \\
\hline
\end{tabular}

${ }^{1} \mathrm{DMI}=\mathrm{kg} / \mathrm{d} ; \mathrm{MY}=$ mean milk yield within study $(\mathrm{kg} / \mathrm{d}) ; \mathrm{CP}=\%$ of $\mathrm{DM} ; \mathrm{NDF}=\%$ of $\mathrm{DM} ; \mathrm{ADF}=\%$ of $\mathrm{DM} ; \mathrm{ADF} / \mathrm{NDF}=\mathrm{ratio}$ of $\mathrm{ADF}$ to $\mathrm{NDF}$ in ration; FNDF = forage NDF ( $\%$ of DM); FNDFD = laboratory measure of forage NDF digestibility (\% of FNDF).

and interactions of FNDFD with both $\mathrm{ADF} / \mathrm{NDF}$ and MY. Our proposed equation is

$$
\begin{gathered}
\text { DMI }(\mathrm{kg} / \mathrm{d})=12.0-0.107 \times \mathrm{FNDF}+8.17 \\
\times \mathrm{ADF} / \mathrm{NDF}+0.0253 \times \mathrm{FNDFD}-0.328 \\
\times(\mathrm{ADF} / \mathrm{NDF}-0.602) \times(\mathrm{FNDFD}-48.3)+0.225 \\
\times \mathrm{MY}+0.00390 \times(\mathrm{FNDFD}-48.3) \times(\mathrm{MY}-33.1)
\end{gathered}
$$

where $\mathrm{FNDF}=$ forage NDF content of diet (\% of DM), $\mathrm{ADF} / \mathrm{NDF}=\mathrm{ADF}$ as a fraction of $\mathrm{NDF}$ in the ration, FNDFD = digestibility of forage NDF measured in vitro or in situ (\% of FNDF), and MY = mean milk yield within study $(\mathrm{kg} / \mathrm{d})$.

The fit statistics for observed versus predicted DMI by the proposed equation and for the 5 -fold cross validation are shown in Table 4 . Because several different factors determine the filling effects of forages and because the number of published studies that have reported complete data related to the filling effects of rations are limited, we chose to use all data to derive the equation rather than reserving data for independent validation. Instead, we used 5 -way cross validation to evaluate the proposed equation. The mean bias was $0.00 \mathrm{~kg} / \mathrm{d}$ with a RMSE of $1.55 \mathrm{~kg} / \mathrm{d}$ and CCC of 0.827 for the proposed equation. The 5-way cross validation resulted in similar fit statistics with a mean bias of
$-0.26 \mathrm{~kg} / \mathrm{d}$, a RMSE of $1.69 \mathrm{~kg} / \mathrm{d}$, and CCC of 0.768 . Although the data set is relatively small, the 5 -way cross validation provides reasonable assurance that the proposed equation will provide acceptable prediction of the effects of ration characteristics on DMI.

Figure 1 shows observed versus predicted DMI for the proposed equation both with and without the random effect of study. The FNDFD was measured differently among studies either in vitro or in situ with no uniform method within each technique and with incubation times of $30,48,72$, or $96 \mathrm{~h}$. Both study and its interaction with the laboratory measure of forage NDF digestibility were initially included in the modeling process because of differences in measurement methods for FNDFD among studies, but the interaction of study and FNDFD was not significant and was removed from the final model. The random effect of study ranged from -2.80 to $1.32 \mathrm{~kg} / \mathrm{d}($ mean $=0.0, \mathrm{SD}=0.92 \mathrm{~kg} / \mathrm{d})$, which accounted for specific differences among studies including methods used to measure ration factors. The equation including study resulted in a RMSE of 1.08 $\mathrm{kg} / \mathrm{d}$ and $\mathrm{CCC}$ of 0.917 compared with a RMSE of $1.55 \mathrm{~kg} / \mathrm{d}$ and CCC of 0.827 without study with no mean bias for either equation (Figure 1). Because the study effect is unknown for application of the proposed equation in the field, the comparison of observed versus predicted without the effect of study is more applicable.

Table 3. Parameter estimates, significance, and variance inflation factors (VIF) for prediction of DMI using ration factors and milk yield

\begin{tabular}{lcccc}
\hline Term $^{1}$ & Estimate & $\mathrm{SE}$ & $P>|\mathrm{t}|$ & $\mathrm{VIF}$ \\
\hline Intercept & 12.0 & 1.7 & $<0.001$ & - \\
FNDF & -0.107 & 0.028 & $<0.001$ & 1.09 \\
ADF $/$ NDF & 8.17 & 2.27 & $<0.001$ & 1.28 \\
FNDFD & 0.0253 & 0.0153 & 0.10 & 1.48 \\
$(\mathrm{ADF} / \mathrm{NDF}-0.602) \times(\mathrm{FNDFD}-48.3)^{2}$ & -0.328 & 0.152 & 0.03 & 1.24 \\
MY & 0.225 & 0.033 & $<0.001$ & 1.80 \\
$($ FNDFD -48.3$) \times(\mathrm{MY}-33.1)^{2}$ & 0.00390 & 0.00203 & 0.06 & 1.52 \\
\hline
\end{tabular}

${ }^{1} \mathrm{NDF}=\%$ of $\mathrm{DM} ; \mathrm{ADF}=\%$ of $\mathrm{DM} ; \mathrm{ADF} / \mathrm{NDF}=$ ratio of $\mathrm{ADF}$ to $\mathrm{NDF}$ in ration; FNDF $=$ forage $\mathrm{NDF}$ ( $\%$ of DM); FNDFD = laboratory measure of forage NDF digestibility ( $\%$ of FNDF); MY = mean milk yield within study $(\mathrm{kg} / \mathrm{d})$.

${ }^{2}$ Continuous predictor variables were centered for interactions. 
Table 4. Fit statistics for the proposed equation using all data and for the 5 -fold cross validation

\begin{tabular}{lcc}
\hline Fit statistic $^{1}$ & All data & Cross validation \\
\hline Observed mean, kg/d & 23.0 & 22.5 \\
Predicted mean, kg/d & 23.0 & 22.3 \\
Mean bias, kg/d & 0.00 & -0.26 \\
RMSE, $\mathrm{kg} / \mathrm{d}$ & 1.55 & 1.69 \\
RMSE, \% of mean & 6.71 & 7.53 \\
CCC & 0.827 & 0.768 \\
\hline
\end{tabular}

${ }^{1} \mathrm{RMSE}=$ root mean square error; $\mathrm{CCC}=$ concordance correlation coefficient.

Prediction profiles are shown for the equation factors in Figure 2 and their significant interactions in Figure 3. The negative relationship between DMI and FNDF concentration is consistent with limitations to DMI by ruminal distention because FNDF is retained in the rumen longer than other ration components and is therefore more filling over time (Allen, 1996) and increasing ration NDF content by substituting forages for concentrates consistently decreased DMI among studies reported in the literature (Allen, 2000).

The ratio of ADF to NDF was included in the model to account for forage type. Feedstuffs fed to dairy cattle vary greatly in ADF/NDF (NRC, 2001, Table 15.1). Legume forages have the highest ADF/NDF $(\sim 0.8)$ followed by cool season grasses $(0.60-0.65)$ and the warm season bermudagrass $(0.47-0.50)$. Cereal grain silages including barley, corn, sorghum, and wheat as well as wheat straw have moderate ADF/NDF (0.60-0.65), and cereal grains including corn, barley, and wheat have the lowest $\mathrm{ADF} / \mathrm{NDF}(0.32-0.35)$. The positive relation-

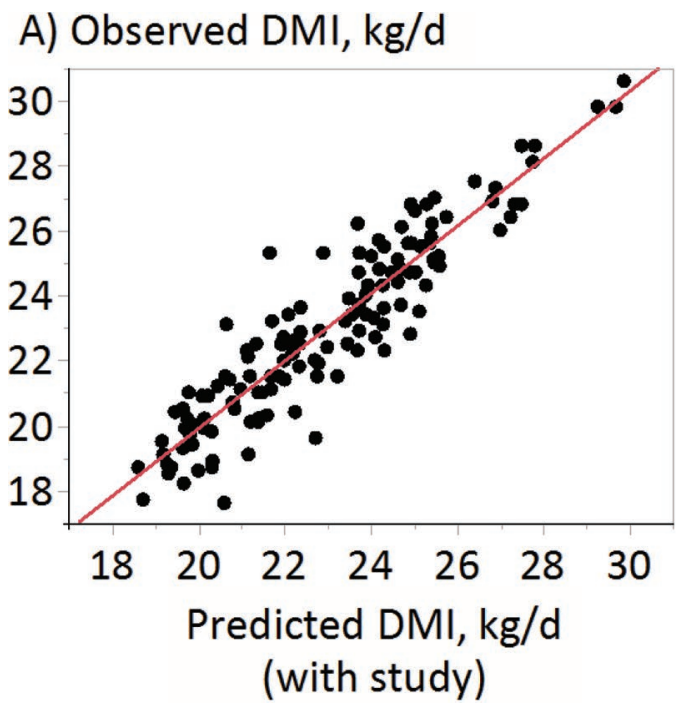

ship between DMI and ration ADF/NDF concentration is consistent with greater DMI for legume than grass forages (Oba and Allen, 1999b). Alfalfa NDF digested and passed from the rumen faster than orchardgrass $\mathrm{NDF}$ and the difference in passage rate increased with DMI (Voelker Linton and Allen, 2008; Kammes and Allen, 2012). The greater rate of passage of alfalfa compared with orchardgrass is likely due to greater fragility because the rate of reduction of large particles was greater for alfalfa than orchardgrass (Kammes and Allen, 2012). However, the relationship between DMI and ration $\mathrm{ADF} / \mathrm{NDF}$ might not be attributable to forage fragility alone. Substitution of cereal grains that have lower $\mathrm{ADF} / \mathrm{NDF}$ for forages with higher $\mathrm{ADF} /$ $\mathrm{NDF}$ is expected to result in a negative relationship between DMI and ADF/NDF because cereal grains are less filling than forages and DMI would be expected to increase (Allen, 2000). However, because cereal grains have low NDF concentration compared with forages, the contribution of cereal grains to the ADF/NDF of rations is much lower than forages. In addition, the cereal grain concentration of rations is likely related to ration concentrations of NDF or FNDF. Ration $\mathrm{ADF} /$ NDF was not related to ration NDF concentration $(P$ $=0.68$ ), but there was a tendency for a correlation with FNDF concentration $(P=0.08)$. Therefore, contribution of cereal grains to the relationship between ration $\mathrm{ADF} / \mathrm{NDF}$ and DMI was likely accounted for by ration FNDF concentration, and the positive relationship between DMI and ration $\mathrm{ADF} / \mathrm{NDF}$ in the proposed equation was likely primarily attributable to differences in forage fragility related to forage type.

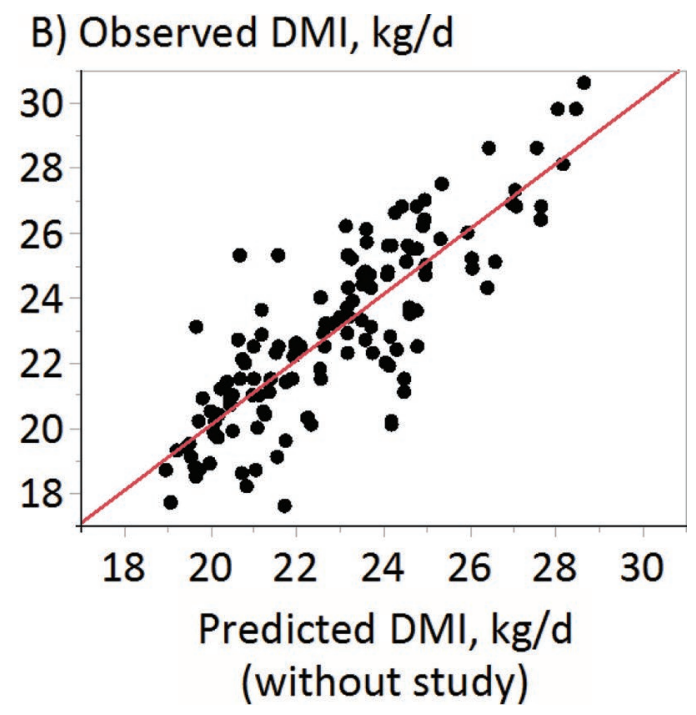

Figure 1. Observed DMI versus predicted DMI including random effect of study [panel A: observed DMI $(\mathrm{kg} / \mathrm{d})=-0.91+1.040 \times$ predicted DMI $(\mathrm{kg} / \mathrm{d})$, root mean square error $(\mathrm{RMSE})=1.08$, mean bias $=0.00 \mathrm{~kg} / \mathrm{d}$, concordance correlation coefficient $(\mathrm{CCC})=0.917]$ and predicted DMI without study effect [panel B: observed DMI $(\mathrm{kg} / \mathrm{d})=-0.05+1.006 \times$ predicted DMI $(\mathrm{kg} / \mathrm{d}), \mathrm{RMSE}=1.55, \mathrm{mean}$ bias $=0.00$ $\mathrm{kg} / \mathrm{d}, \mathrm{CCC}=0.827]$. 


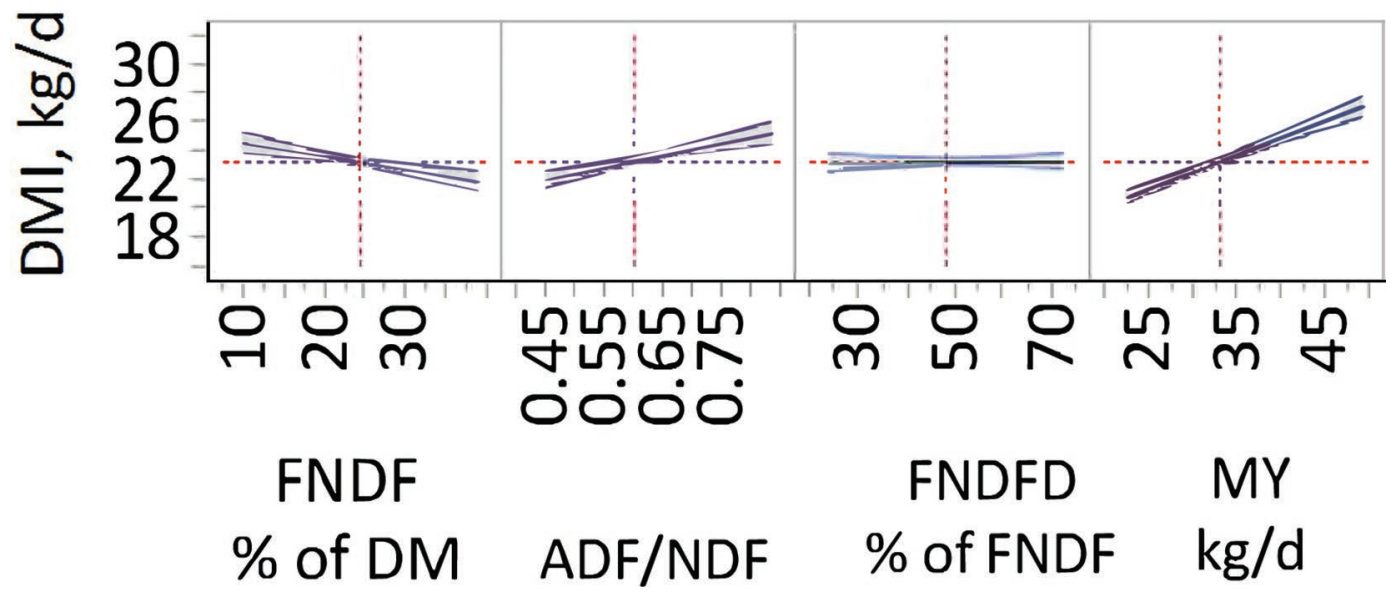

Figure 2. Prediction profiles for effects of ration forage NDF concentration as a percent of ration DM (FNDF), the ratio of ration ADF to NDF concentration (ADF/NDF), laboratory measure of forage NDF digestibility as a percent of FNDF (FNDFD), and mean milk yield (MY; $\mathrm{kg} / \mathrm{d})$ within study on DMI $(\mathrm{kg} / \mathrm{d})$. The solid lines represent the relationship between the individual factor and DMI with other factors held constant at their means. The shaded area around the solid lines is the $95 \% \mathrm{CI}$, the vertical broken lines show the mean for the factor of interest, and the horizontal lines show the mean DMI.

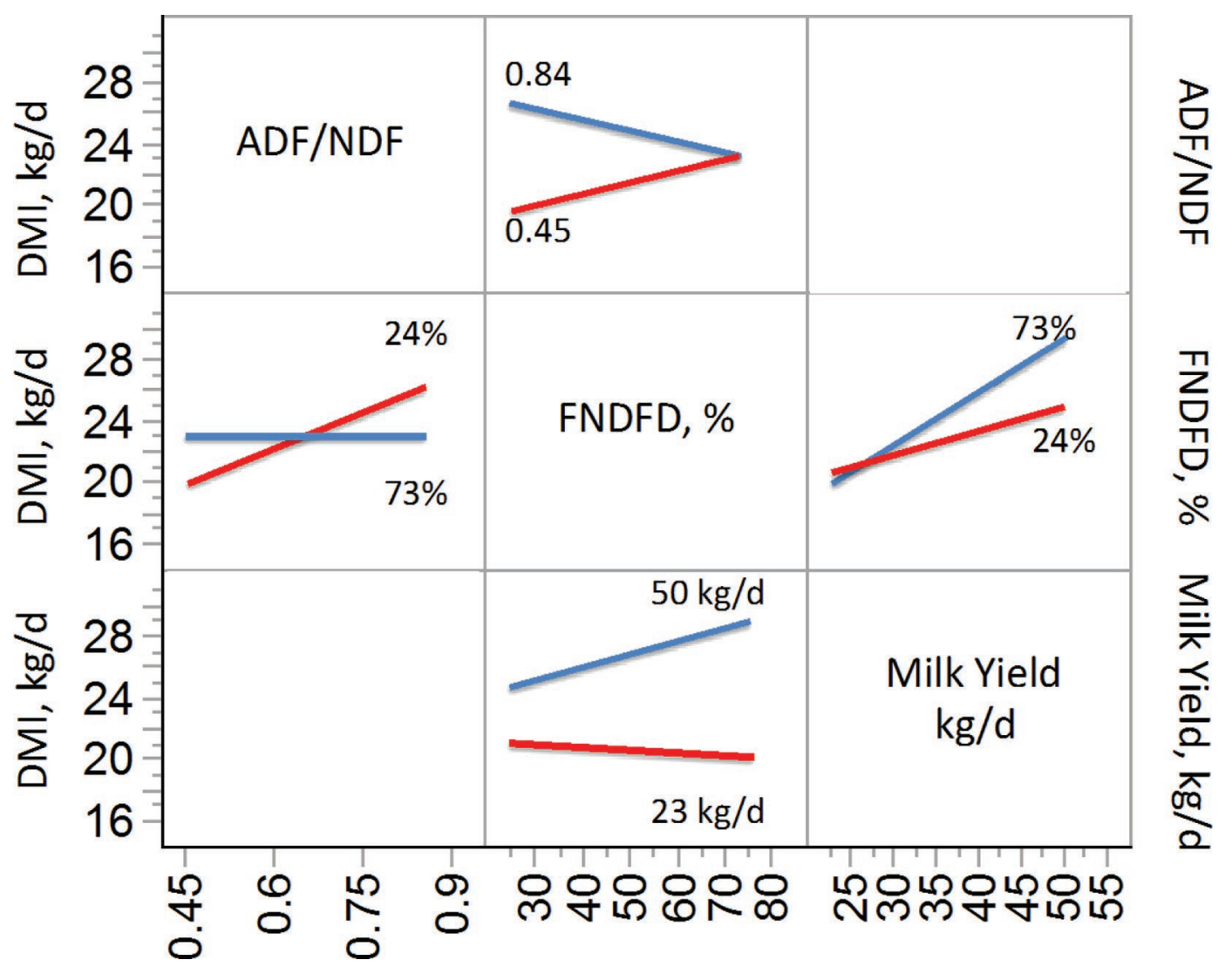

Figure 3. Prediction profiles for interactions of laboratory measure of forage NDF digestibility, as a percent of forage NDF (FNDFD), with ration $\mathrm{ADF} / \mathrm{NDF}$ and mean study milk yield $(\mathrm{MY} ; \mathrm{kg} / \mathrm{d})$ on DMI $(\mathrm{kg} / \mathrm{d})$. The DMI is on the $\mathrm{y}$-axis of each plot, and the $\mathrm{x}-\mathrm{axis}$ represents $\mathrm{ADF} / \mathrm{NDF}, \mathrm{FNDFD}$, and MY from left to right. The 2 lines in each plot show the interaction of the factor labeled on each row with the factor represented on the $\mathrm{x}$-axis. 
The positive relationship between DMI and MY was expected as more nutrients are required for milk production as MY increases. Milk yield was included as a potential factor in the model because we expected it to interact with factors related to the filling effect of rations. Distention likely becomes a more dominant mechanism limiting DMI as MY increases; DMI response to increased ration FNDF (Voelker at al., 2002) and in vitro forage NDFD (Oba and Allen, 1999a) was positively related to MY among cows. However, ration factors can affect both DMI and MY, so including MY diminishes their effects. In addition, rations with high FNDF are not generally offered to cows with high MY, causing a false correlation. We included the mean MY within study rather than the MY for individual treatments to help minimize these effects. We did not include FCM or ECM because they are not necessary to represent the increased limitation on DMI by ruminal distention as MY increases. In addition, they are likely less related to the limitation of DMI by distention because of the positive relationship between the filling effects of diets and milk fat concentration.

Milk yield did not interact with ration FNDF or $\mathrm{ADF} / \mathrm{NDF}$ to affect DMI. Although FNDFD was not correlated with DMI (Table 2), it interacted with MY to affect DMI (Figure 3); DMI and FNDFD were related positively for cows with high MY but related negatively for cows with low MY (interaction $P=$ 0.06), diminishing the overall effect of FNDFD on DMI $(P=0.10$, Table 3$)$. In addition, DMI increased with MY to a greater extent for high FNDFD compared with low FNDFD. The positive relationship between DMI and FNDFD for cows with high MY and greater DMI response for high compared with low FNDFD as MY increased is consistent with greater limitation to DMI by distention as MY increases. Oba and Allen (1999a) reported a positive relationship between DMI response to increased FNDFD to a decreased filling ef- fect of brown midrib compared with normal corn silage. In addition, a meta-regression of treatment means from the literature showed a positive relationship between DMI and FNDFD within forage family (Oba and Allen, 1999b). The slight negative relationship between DMI and FNDFD for cows with low MY shown in Figure 3 might have been because DMI was less likely limited by ruminal distention for these cows and more limited by mechanisms related to metabolic effects of fuels. Consistent with this, DMI response to greater in vitro FNDFD was negatively related to response for totaltract NDF digestibility in a study comparing brown midrib to normal corn silage with a positive response in NDFD when DMI decreased and a negative response in NDFD when DMI increased (Oba and Allen, 1999a).

Dry matter intake and FNDFD were related positively for low ration $\mathrm{ADF} / \mathrm{NDF}$ but related negatively for high ration $\mathrm{ADF} / \mathrm{NDF}$. Also, $\mathrm{DMI}$ and ration $\mathrm{ADF} /$ NDF were related positively when FNDFD was low, but DMI was not affected by ration $\mathrm{ADF} / \mathrm{NDF}$ when FNDFD was high. As discussed previously, grass forages have lower $\mathrm{ADF} / \mathrm{NDF}$ and are more filling than legume forages and might be expected to have a greater DMI response to increased FNDFD than legumes. However, whereas DMI and FNDFD were related negatively across forage family, they were related positively within grasses and legumes (Oba and Allen, 1999b). If ADF/ NDF is related to forage type in this data set, it is not clear why DMI and FNDFD were related negatively for high ration $\mathrm{ADF} / \mathrm{NDF}$. It is possible that this relationship was affected by the overall effect of ration $\mathrm{ADF} /$ NDF or the interaction of FNDFD and MY discussed previously.

\section{Comparison with the NRC (2001) DMI Equation}

To compare the proposed equation to the NRC (2001) equation they both needed to be fit to the same data.

Table 5. Description of the subset of the data set (91 of the 134 treatment means) used to compare the proposed model including ration factors with the general form of the equation recommended by NRC (2001) including only animal factors

\begin{tabular}{llcccc}
\hline Item & Variable $^{1}$ & Mean & SD & Minimum & Maximum \\
\hline Animal factors & DMI, kg/d & 23.5 & 2.6 & 17.6 & 30.6 \\
& DIM & 99 & 27 & 61 & 162 \\
& $4 \%$ FCM, kg/d & 30.3 & 7.4 & 18.6 & 48.1 \\
& BW, kg & 643 & 59 & 497 & 765 \\
Ration factors & MY, kg/d & 32.6 & 7.4 & 23.4 & 49.7 \\
& NDF, \% of DM & 34.8 & 4.6 & 25.9 & 48.2 \\
& ADF, \% of DM & 21.3 & 4.0 & 13.0 & 31.0 \\
& ADF/NDF & 0.612 & 0.081 & 0.46 & 0.77 \\
& FNDF, \% of DM & 23.0 & 5.9 & 9.9 & 39.3 \\
& FNDFD, \% of FNDF & 50.8 & 11.3 & 24.1 & 72.7 \\
\hline
\end{tabular}

${ }^{1} \mathrm{FCM}=4 \%$ fat-corrected milk; $\mathrm{MY}=$ mean of milk yield across studies; ADF $/ \mathrm{NDF}=$ ratio of ADF to NDF in rations; FNDF = forage NDF; FNDFD = laboratory measure of forage NDF digestibility. 
Table 6. Parameter estimates, significance, and variance inflation factors (VIF) for prediction of DMI using the general form of the equation recommended by NRC (2001) including only animal factors

\begin{tabular}{lcccc}
\hline Term $^{1}$ & Estimate & SE & $P>|\mathrm{t}|$ & VIF \\
\hline FCM $^{0.75}$ & 0.218 & 0.049 & $<0.001$ & 20.8 \\
lW $^{0}$ & 0.132 & 0.012 & $<0.001$ & 20.8 \\
\hline
\end{tabular}

${ }^{1} \mathrm{FCM}=4 \%$ fat-corrected milk yield.

Because no other data were available, both were fit to a subset of the data (Table 5). Fitting the NRC (2001) equation to the subset of data changed the estimates for FCM from 0.372 to 0.218 and for $\mathrm{BW}^{0.75}$ from 0.0968 to 0.132 (Table 6 ). The observed DMI versus predicted DMI (Figure 4) resulted in a better fit to the data for the proposed equation compared with the NRC (2001) equation with a lower RMSE (1.62 vs. $1.87 \mathrm{~kg} / \mathrm{d}$ ), a higher CCC (0.767 vs. 0.696), a smaller intercept (1.49 vs. $5.82 \mathrm{~kg} / \mathrm{d}$ ), and a slope closer to unity (0.947 vs. $0.761)$. Although mean bias was the same for the 2 equations, the NRC (2001) equation over-predicted DMI for cows with high DMI, and under-predicted DMI for cows with low DMI. Similar bias was shown for equations based on only animal factors using a much larger data set when the equation recommended by NRC (2001) was compared with an updated equation (de Souza et al., 2019). Over-prediction of DMI at high DMI is likely because ruminal distention increasingly limits DMI as MY (and DMI) increase and under-prediction of DMI at low DMI is likely because excess energy was partitioned to body condition. Including ration factors and their interaction with MY in prediction equations corrects for both, improving the fit to the data.

\section{Use and Limitations of the Proposed Equation}

Whereas we suggest that DMI should be predicted at the initial stages of ration formulation using an equation developed with only animal factors based upon much larger data sets, the proposed equation is useful to predict the effect of ration composition on DMI during the process of ration formulation. However, the proposed equation has several limitations and unknowns. Control of DMI by cows in the postpartum period is more likely dominated by metabolic mechanisms rather than mechanisms related to the filling effect of the ration (Allen, 2014). In addition, few studies with cows in early lactation reported a measure of forage NDF digestibility. Our data set included data for cows greater than $60 \mathrm{~d}$ postpartum only. Therefore, use of the proposed equation should be limited to cows past 60 d postpartum. In addition, our data set included studies with Holstein cows only. Although treatment means for BW among studies in our data set ranged from 497 to $765 \mathrm{~kg}$ (Table 1) and BW was eliminated during the stepwise regression, the suitability of the proposed equation for smaller breeds is unknown.

The data set did not include treatments of nonforage fiber sources (NFFS), but inclusion of NFFS in rations has been shown to have little effect on DMI of lactating cows (Allen, 2000). However, the ADF/NDF of NFFS varies widely [e.g., corn gluten feed (0.34), beet pulp
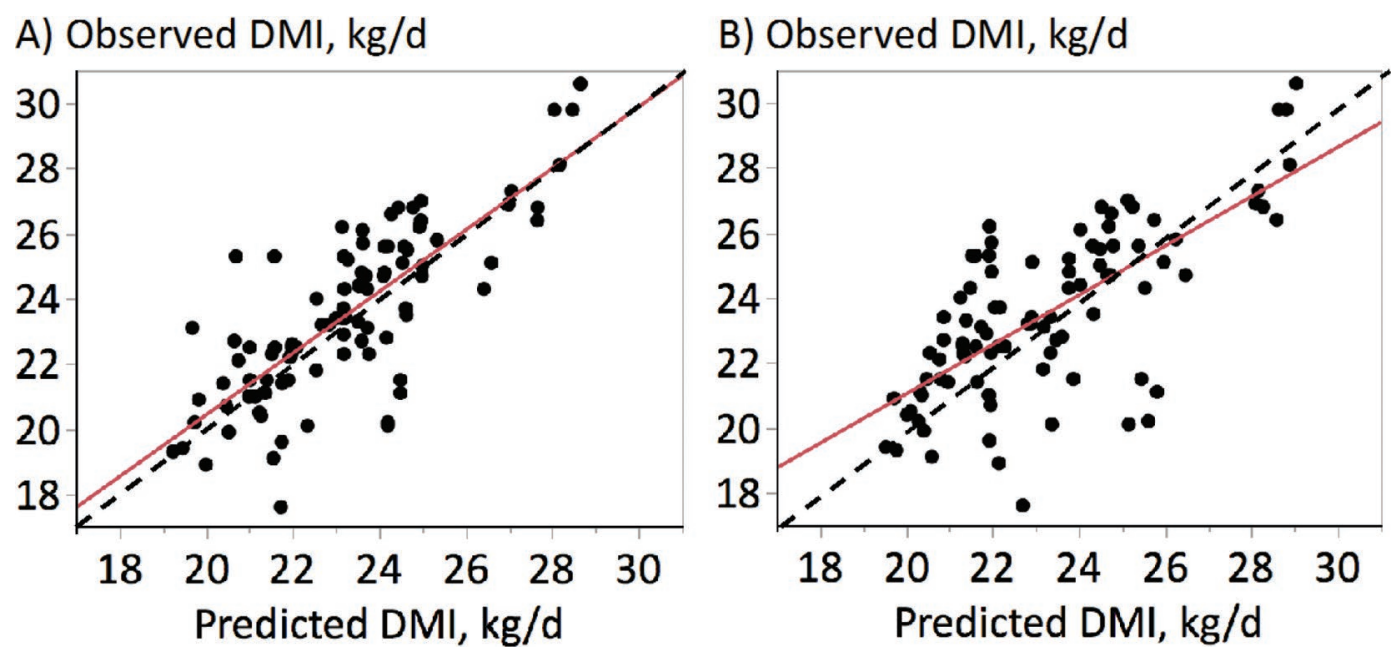

Figure 4. Observed DMI $(\mathrm{kg} / \mathrm{d})$ versus predicted DMI $(\mathrm{kg} / \mathrm{d})$ for the proposed equation including ration effects [panel A: observed DMI $(\mathrm{kg} / \mathrm{d})=1.49+0.947 \times$ predicted DMI $(\mathrm{kg} / \mathrm{d})$, root mean square error $(\mathrm{RMSE})=1.62 \mathrm{~kg} / \mathrm{d}$, mean bias $=0.00 \mathrm{~kg} / \mathrm{d}$, concordance correlation coefficient $(\mathrm{CCC})=0.767]$ and for the NRC (2001) equation including only animal factors (panel B: observed DMI, $\mathrm{kg} / \mathrm{d}=5.82+0.761$ $\times$ predicted DMI, $\mathrm{kg} / \mathrm{d}, \mathrm{RMSE}=1.87 \mathrm{~kg} / \mathrm{d}$, mean bias $=0.00 \mathrm{~kg} / \mathrm{d}, \mathrm{CCC}=0.696)$. The subset including 91 of the 134 means of the data set with complete data was used (Table 5). 
(0.50), soyhulls (0.74), almond hulls (0.78), and whole cottonseed (0.80)]. Therefore, evaluating effects of large changes in NFFS on DMI is not recommended. In addition, we did not include measures of forage particle size in the data set. Only 3 of 20 comparisons reported in the literature reported a significant effect of forage particle length on DMI when the same source of forage (hay or silage) was chopped at 2 or more lengths (Allen, 2000). However, inclusion of forages with long particle length in high forage rations has been shown to reduce DMI (Beauchemin et al., 1994), which might be a limitation for this equation. Dry matter intake is affected by factors other than those related to rumen fill including the fermentability of starch in the ration (Allen, 2000), ration protein concentration (Roffler et al., 1986; Allen, 2000), silage fermentation quality (Huhtanen et al., 2002), and the amount and type of fat in the ration (Allen, 2000; Rabiee et al., 2012; Weld and Armentano, 2017), and this equation will not be responsive to changes in these factors.

The rations included in these studies contained a single forage, or other forages contributed little to the diet and did not change within study. It is suggested that a weighted average be used for FNDFD when this equation is used to predict DMI for rations with multiple forages. If FNDFD values are not available, mean FNDFD of the data set should be used. In addition, because it is a biological assay with expected variation across runs, FNDFD for all forage comparisons should be measured with the same method and retention time and preferably within the same run or corrected using the same laboratory standard.

\section{CONCLUSIONS}

The filling effects of rations can limit DMI, particularly as MY increases. Equations that include only animal factors likely over-predict DMI for high-producing cows because they do not account for the effects of fill on DMI. The proposed equation to predict DMI contains factors related to the filling effects of rations including forage NDF concentration, ration $\mathrm{ADF} / \mathrm{NDF}$, and forage NDF digestibility as well as MY. We suggest that it be used during ration formulation to predict the effect of ration changes on DMI of lactating cows.

\section{ACKNOWLEDGMENTS}

We acknowledge fellowship support to D.O.S. from the Fundação de Amparo à Pesquisa do Estado de São Paulo, Brazil (Process: 2015/02435-0).

\section{REFERENCES}

Allen, M. S. 1996. Physical constraints on voluntary intake of forages by ruminants. J. Anim. Sci. 74:3063-3075. https://doi.org/10 $.2527 / 1996.74123063 x$.

Allen, M. S. 2000. Effects of diet on short-term regulation of feed intake by lactating dairy cattle. J. Dairy Sci. 83:1598-1624. https:// doi.org/10.3168/jds.S0022-0302(00)75030-2

Allen, M. S. 2014. Drives and limits to feed intake in ruminants. Anim. Prod. Sci. 54:1513-1524. https://doi.org/10.1071/AN14478.

Beauchemin, K. A., B. I. Farr, L. M. Rode, and G. B. Schaalje. 1994. Effects of alfalfa silage chop length and supplementary long hay on chewing and milk production of dairy cows. J. Dairy Sci. 77:13261339. https://doi.org/10.3168/jds.S0022-0302(94)77072-7.

de Souza, R. A., R. J. Tempelman, M. S. Allen, and M. J. VandeHaar. 2019. Updating predictions of dry matter intake of lactating dairy cows. J. Dairy Sci. 102:7948-7960. https://doi.org/10.3168/ jds.2019-16176.

Huhtanen, P., H. Khalili, J. I. Nousiainen, M. Rinne, S. Jaakkola, T. Heikkila, and J. Nousiainen. 2002. Prediction of the relative intake potential of grass silage by dairy cows. Livest. Prod. Sci. 73:111130. https://doi.org/10.1016/S0301-6226(01)00279-2.

Huhtanen, P., M. Rinne, P. Mantysaari, and J. Nousiainen. 2011. Integration of the effects of animal and dietary factors on total dry matter intake of dairy cows fed silage-based diets. Animal 5:691702. https://doi.org/10.1017/S1751731110002363.

Ingvartsen, K. L. 1994. Models of voluntary food intake in cattle. Livest. Prod. Sci. 39:19-38. https://doi.org/10.1016/0301 $-6226(94) 90149-\mathrm{X}$.

Kammes, K. L., and M. S. Allen. 2012. Rates of particle size reduction and passage are faster for legume compared to cool-season grass, resulting in lower rumen fill and less effective fiber. J. Dairy Sci. 95:3288-3297. https://doi.org/10.3168/jds.2011-5022.

Krizsan, S. J., A. Sairanen, A. Höjer, and P. Huhtanen. 2014. Evaluation of different feed intake models for dairy cows. J. Dairy Sci. 97:2387-2397. https://doi.org/10.3168/jds.2013-7561.

NRC. 2001. Nutrient Requirements of Dairy Cattle. 7th rev. ed. Natl. Acad. Press, Washington, DC.

Oba, M., and M. S. Allen. 1999a. Effects of brown midrib 3 mutation in corn silage on dry matter intake and productivity of high yielding dairy cows. J. Dairy Sci. 82:135-142. https://doi.org/10.3168/ jds.S0022-0302(99)75217-3.

Oba, M., and M. S. Allen. 1999b. Evaluation of the importance of the digestibility of neutral detergent fiber from forage: effects on dry matter intake and milk yield of dairy cows. J. Dairy Sci. 82:589 596. https://doi.org/10.3168/jds.S0022-0302(99)75271-9.

Rabiee, A. R., K. Breinhild, W. Scott, H. M. Golder, E. Block, and I. J. Lean. 2012. Effect of fat additions to diets of dairy cattle on milk production and components: A meta-analysis and metaregression. J. Dairy Sci. 95:3225-3247. https://doi.org/10.3168/ jds.2011-4895.

Roffler, R. E., J. E. Wray, and L. D. Satter. 1986. Production responses in early lactation to additions of soybean meal to diets containing predominantly corn silage. J. Dairy Sci. 69:1055-1062. https://doi.org/10.3168/jds.S0022-0302(86)80501-X.

Voelker, J. A., G. M. Burato, and M. S. Allen. 2002. Effects of pretrial milk yield on responses of feed intake, digestion, and production to dietary forage concentration. J. Dairy Sci. 85:2650-2661. https:// doi.org/10.3168/jds.S0022-0302(02)74350-6.

Voelker Linton, J. A., and M. S. Allen. 2008. Nutrient demand interacts with forage family to affect intake and digestion responses in dairy cows. J. Dairy Sci. 91:2694-2701. https://doi.org/10.3168/ jds.2007-0897.

Weld, K. A., and L. E. Armentano. 2017. The effects of adding fat to diets of lactating dairy cows on total-tract neutral detergent fiber digestibility: A meta-analysis. J. Dairy Sci. 100:1766-1779. https:/ /doi.org/10.3168/jds.2016-11500. 